\title{
Post-release survival of orphaned wild-born polecats Mustela putorius reared in captivity at a wildlife rehabilitation centre in England
}

\author{
Andrew Kelly ${ }^{1,2, *}$, Robert Scrivens ${ }^{1}$, Adam Grogan ${ }^{3}$ \\ ${ }^{1}$ RSPCA Stapeley Grange Wildlife Centre, London Rd., Stapeley, Nantwich, Cheshire CW5 7JW, UK \\ ${ }^{2}$ School of Biological Sciences, Medical Biology Centre, Queen's University Belfast, 97 Lisburn Road, \\ Belfast BT9 7BL, UK \\ ${ }^{3}$ RSPCA, Wildlife Department, Wilberforce Way, Southwater, Horsham, West Sussex RH13 9RS, UK
}

\begin{abstract}
Many thousands of rehabilitated wildlife casualties and captive-reared orphans are released back to the wild each year. Most wildlife rehabilitators equate release with success, and very little is known about the post-release survival of rehabilitated wildlife. We measured the postrelease survival of orphaned polecats Mustela putorius, a species of conservation concern and currently a UK Biodiversity Action Plan (BAP) priority species. Between 1997 and 2008, 137 polecats were admitted to the RSPCA (Royal Society for the Prevention of Cruelty to Animals) Stapeley Grange Wildlife Centre in northwest England. Of these, 89 (65\%) were orphaned juveniles. Fortythree percent of adults and $89 \%$ of juveniles were released back to the wild following rehabilitation. Between 2005 and 2008, we radio-tracked 32 juvenile polecats at 5 release sites in Cheshire and North Wales, UK. These individuals were tracked for 3 to $104 \mathrm{~d}$ (median $=27.5$ ). Of the 32 radiotracked animals, $26(81 \%)$ were still alive after $14 \mathrm{~d}$, and a minimum of $16(50 \%)$ were still alive after 1 mo. Twelve percent were known to have died in road traffic collisions, $22 \%$ shed their collars, and the signal was lost for $56 \%$. Those for which the signal was eventually lost were tracked for 13 to $103 \mathrm{~d}$ (median $=38.5 \mathrm{~d}$ ). Two female polecats trapped following release in 2007 had lost $30 \%$ and $18 \%$ of their body weight, respectively. The data suggest that the survival of rehabilitated polecats is sufficient to justify the resources used in the rehabilitation process and that the animals' long-term welfare is not compromised by being held in captivity.
\end{abstract}

KEY WORDS: Polecat $\cdot$ Mustela putorius $\cdot$ Post-release survival $\cdot$ Wildlife rehabilitation $\cdot$ Restoration ecology Resale or republication not permitted without written consent of the publisher

\section{INTRODUCTION}

Large numbers of captive-bred and wild caught animals are released into the wild annually, often as part of conservation or translocation strategies (e.g. Wolf et al. 1996, Moorhouse 2004, Mathews et al. 2005, 2006, Maran et al. 2009, Peters et al. 2009, Pinter-Wollman et al. 2009). These include the reintroduction of captiveborn animals and/or the translocation of wild-caught animals. However, reintroduction of captive-bred animals and translocation of wild-caught animals into the wild have had low levels of success (Beck et al. 1994, Ginsberg 1994, Mathews et al. 2005, Jule et al. 2008). In a survey of translocation programmes in North America, Australia and New Zealand, Griffith et al. (1989) concluded that only $44 \%(\mathrm{~N}=80)$ of translocations of endangered or threatened avian and mammalian species could be described as successful. Translocations of wild-caught animals were more likely to succeed than releasing captive-bred animals (Griffith et al. 1989). A review of these programmes some years later revealed an increase in the number of programmes in which the population was self-sustaining (Wolf et al. 1996), with $53 \%$ of programmes involving endangered or threatened avian and mammalian species being described as successful. However, when native game species 
were included, the overall success rate was $66 \%$ and $67 \%$ in the 2 studies, respectively (Griffith et al. 1989, Wolf et al. 1996). More recently, Fischer \& Lindenmayer (2000) assessed the published results of reintroduction, translocation and supplementation programmes over a $20 \mathrm{yr}$ period and found that reintroduction success had not changed over the time period surveyed. Of 116 reintroductions, only $26 \%$ were considered to be successful, although the outcome of $47 \%$ was classified as 'uncertain', highlighting the need for continual monitoring and reporting. Reintroductions did appear to be more successful when source animals were wildborn $(31 \%$ versus $13 \%)$, but other factors such as the number of animals released and persistence of the original reason for the species decline were also shown to be important (Fischer \& Lindenmayer 2000). Although the use of wild-born animals in restoration projects may be more successful than using captive-bred individuals (Fischer \& Lindenmayer 2000, Hayward et al. 2007, Jule et al. 2008), translocating wild animals to unfamiliar habitats or territories may affect their welfare (Molony et al. 2006, Moorhouse et al. 2007, PinterWollman et al. 2009). Sub-optimal habitat and naivety to the local environment may lead to competitioninduced stress, exposure to disease and vulnerability to predation. This may result in a reduction in survival or an inability to integrate with the population (Sarrazin \& Legendre 2000, Bar-David et al. 2005, Letty et al. 2007, Pinter-Wollman et al. 2009). Releasing animals into locations that are already occupied can have an effect on the existing population and could also prove fatal to the resident and/or released animals. The low success rate of these strategies emphasises the need for postrelease monitoring of reintroduced or translocated animals to determine their post-release survival and whether their welfare has been compromised (Macdonald 2009).

The rehabilitation of sick, injured or orphaned wildlife is a growing source, globally, of wild animals being released into the wild. In the UK, the Royal Society for the Prevention of Cruelty to Animal's (RSPCA) 4 wildlife centres admit over 14000 wildlife casualties annually. Release rates range from 25 to $90 \%$, depending on species and reason for admission/severity of injury (Kelly \& Bland 2006, Molony et al. 2007). Although $75 \%$ of admissions are birds, many orphaned mammals are also admitted, including hedgehogs Erinaceus europaeus, red foxes Vulpes vulpes, badgers Meles meles, pipistrelle bats (Pipistrellus spp.) and polecats Mustela putorius.

Polecats are widespread in western Europe, where their status is either uncertain or is showing signs of decline (Birks \& Kitchener 2008). In Britain, although formerly widespread, the polecat was subjected to a severe range contraction and decline in numbers dur- ing the 19th century, resulting in its population being mainly restricted to a small refuge in mid-Wales by the early 20th century (Langley \& Yalden 1977). This decline was largely due to intense persecution by gamekeepers, associated with sporting estates (Langley \& Yalden 1977, Packer \& Birks 1999). However, the range of polecats has expanded in Britain over the last 5 decades, largely due to reduced persecution, an increase in the numbers of rabbits Oryctolagus cuniculus and because they are habitat generalists (Blandford 1987, Birks \& Kitchener 1999, Birks 2008). The polecat is now widely re-established in central England and Wales, with small, outlying populations in northern England and Scotland (Birks 2008). The population has been estimated at about 48000 , representing an annual increase of $2.4 \%$ since 1997 (Birks 2008), mostly in England. Polecats are currently listed as a species of conservation concern and have recently been listed as a UK Biodiversity Action Plan (BAP) priority species.

Most recorded polecat mortality in Britain is due to anthropomorphic causes, with road traffic collisions (RTCs) being responsible for $68 \%$ of mortality in a population in the English Midlands (Birks 2000). Although males are generally more at risk of RTCs than females, during the main lactation and weaning period (June), females are more vulnerable to RTCs than males (Birks \& Kitchener 1999). At this time of year, orphaned kits may be found by members of the public and brought to wildlife rehabilitation centres, where they are handreared and released later in the same year.

Unfortunately, many wildlife rehabilitators equate release back into the wild with success (Sharp 1996), and very little is known about the post-release survival of rehabilitated wildlife. Rescued wild-born and subsequently hand-reared animals may fare less well than animals raised in captivity by their parents. This could potentially result from poor diet in captivity (less than appropriate milk replacers for example), lack of opportunity to learn or develop social skills resulting in inappropriate social responses to conspecifics (particularly if imprinted on humans), lack of opportunity to learn how to hunt, lack of familiarity with local prey, and the possibility that rescued wildlife may be poor quality in relation to other individuals in the population. Captivity itself may result in increased cumulative effects of stress (Moorhouse et al. 2007). However, the effect of stress is rarely considered in translocation, reintroduction or wildlife rehabilitation programmes (Teixeira et al. 2007, Linklater et al. 2010). Yet, captivity may confer benefits, as animals can build up or replace fat reserves, which may be vital when relocated to a new area (Molony et al. 2006).

Wildlife rehabilitation is often criticised by conservationists as being of little value to the conservation of 
the species involved and a waste of time and resources (Sharp 1996). If rehabilitated wildlife casualties are unable to integrate with the wild population and demonstrate normal behaviour, their welfare may be compromised, the animals could suffer and many may be unable to survive. The wildlife rehabilitation community therefore has a responsibility to demonstrate that the post-release survival of rehabilitated casualties is sufficient to justify the rehabilitation process.

Some studies have focussed on the factors affecting the likelihood of release of rescued wildlife (Kelly \& Bland 2006, Molony et al. 2007). These studies have demonstrated that it is possible to use factors such as body condition, age, sex and clinical diagnosis to determine the likelihood of release back to the wild. However, few studies have investigated the survival and behaviour of rehabilitated wildlife following release. In the UK, the RSPCA has recognised that the welfare of rehabilitated animals may be compromised if they do not have the skills required to survive in the wild following release. To that end, the RSPCA has recently embarked on a programme of post-release monitoring of a wide range of rehabilitated wildlife species, using survival as a benchmark of success. For example, the RSPCA has measured the post-release survival of hand-reared, orphaned pipistrelle bats (Pipistrellus spp.) using radio-tracking (Kelly et al. 2008) and juvenile tawny owls Strix aluco using both radiotracking and leg-band recovery data (Leighton et al. 2008). These studies have demonstrated post-release survival times that justify the resources invested in the rehabilitation process. To our knowledge, RSPCA Stapeley Grange in Cheshire, UK, is the only wildlife rehabilitation centre in the UK to care frequently for and release orphaned polecats. Owing to the welfare concerns outlined above and the considerable resources invested in caring for these animals, it is vital that they are monitored post-release and their survival and behaviour assessed.

Here, we retrospectively examined the clinical record cards of polecats admitted to RSPCA Stapeley Grange Wildlife Centre between 1997 and 2008. We describe the reasons for admission and outcomes for adults and juveniles. We tested the hypothesis that hand-reared, orphaned polecats could survive independently in the wild by radio-tracking 32 orphaned polecats between 2005 and 2008 to measure their postrelease survival. Rehabilitation was considered to be successful if the animals were still alive after 1 mo. In addition, a small number of released polecats were trapped (under licence from Natural England) following release to monitor their body condition. We discuss our results in the context of criticism aimed at wildlife rehabilitation and the ethical implications of interventions for the welfare of wildlife casualties.

\section{MATERIALS AND METHODS}

Admission reasons and outcomes. All polecats were examined by a veterinary surgeon on admission to Stapleley Grange, and those considered unsuitable for rehabilitation due to the severity of injury were euthanised to prevent further suffering. The reasons for admission were recorded as: collision (usually with cars); trapped; injury (cause unknown); weakness; orphan; other (abnormal behaviour, bite wound, tame). For individual recognition, all polecats suitable for rehabilitation were microchipped on admission using Animal Identification Transponders $(12 \times 2.12 \mathrm{~mm}$, Petlog) implanted subcutaneously between the scapulae.

All polecats were weighed on admission and their body condition assessed. The following information was recorded: weight, age (adult or juvenile), sex, and date and location found. Age was determined by examining the teeth, pelage and in males whether the testicles had descended. Weight in relation to time of year when animals were admitted was also taken into account.

Orphaned juvenile polecat kits were socialised into groups of 4 to 5 to mimic the litter size found in wild polecats. Animals were kept in caged runs with a wood chip substrate measuring $7 \times 1.52 \times 2.44 \mathrm{~m}$ (height $\times$ width $\times$ length), containing an area for them to sleep and plastic tubing to mimic rabbit burrows. Diet consisted of dead mice and fresh rabbit carcasses to give them the opportunity to deal with natural food sources.

Radio-tracking. Between 2005 and 2008, 32 fullygrown juvenile polecats were fitted with TW3 transmitters fitted on teflon collars (Biotrack), under sedation whilst undergoing a final veterinary health check $1 \mathrm{wk}$ prior to release. Anaesthesia was induced by administering 5\% isoflurane (Isoflo, Abbott Animal Health) by mask, with the animals allowed to recover in air following the health check and transmitter attachment.

The collars, including the transmitters, weighed approximately $15 \mathrm{~g}$ and accounted for less than $2 \%$ of the body weight of the polecats on release. The transmitters included a mortality sensor with the pulse rate doubling if the tag was stationary for $6 \mathrm{~h}$ or more. If the tag subsequently moved, the pulse rate was reset to the original rate, until the tag was stationary for a further $6 \mathrm{~h}$. The battery life of the transmitters was approximately $3 \mathrm{mo}$, with an approximate range of $1 \mathrm{~km}$.

Polecats were allowed to recover before being returned to their pens where they were observed for $7 \mathrm{~d}$ prior to release to ensure that the collars were not causing any welfare concerns. All polecats were weighed on the day of release. 
Polecats were radio-tracked from $22: 00 \mathrm{~h}$ to $06: 00 \mathrm{~h}$ at night for $1 \mathrm{wk}$ following release, with fixes being taken at 30 min intervals. An attempt was made to locate each polecat once during daylight (daily following release) until approximately $7 \mathrm{~d}$ after the last contact was made. Fixes were taken on foot, using triangulation to locate the focal animal (White \& Garrott 1990).

Release protocol. In Britain, polecats are found in a wide range of habitats but are generally associated with lowland woodland edge, field boundaries and farm buildings in areas with high rabbit abundance (Birks 2008). Release sites were chosen to include these habitat types but also taking into account the proximity of game-rearing and busy roads. Abundance of rabbits was taken into consideration, as rabbits ac- counted for $85 \%$ of the diet of polecats in a West Midlands population study (Birks \& Kitchener 1999). Most polecats were released between September and October (Table 1), which corresponds to the time that young wild polecats disperse from the mother (Birks 2008). One group of 3 polecats was released in November 2005 due to practical and operational reasons (Table 1). To maximise the chances of survival, a soft-release protocol was used for all juvenile animals. Once the juvenile polecats were deemed capable of independent living, a soft-release enclosed pen measuring $1.83 \times 1.83 \times$ $3.66 \mathrm{~m}$ (height $\times$ width $\times$ length), was constructed at the release site. The release pens were constructed in an area of shade and hidden from view to minimise disturbance to the animals. The pens consisted of a solid iron structure with $2.5 \mathrm{~mm}$ mesh and dug approximately

Table 1. Mustela putorius. Fate of all 32 polecats radio-tracked between 2005 and 2008. M: male, F: female. C1, C2, C3: release sites in Cheshire (England), NW: release site in North Wales, S: release site in Shropshire (England). RTC: road traffic collision. The figures in parentheses in the final column show the number of days post-release for those polecats subsequently found dead (RTC). Body weights on release include the weight of the collar (15 g). Dates are dd/mm/yy. NR: not recorded

\begin{tabular}{|c|c|c|c|c|c|c|c|}
\hline Polecat & Sex & Release site & Release weight (g) & Release date & Last contact date & Fate & Days \\
\hline 1 & M & $\mathrm{C} 1$ & 1808 & $17 / 09 / 05$ & 05/10/05 & Lost signal & $18(172)$ \\
\hline 2 & M & C1 & 1446 & $17 / 09 / 05$ & 16/11/05 & Lost signal & $58(68)$ \\
\hline 3 & M & $\mathrm{C} 1$ & 1578 & $17 / 09 / 05$ & $17 / 11 / 05$ & Lost signal & 59 \\
\hline 4 & M & $\mathrm{C} 1$ & 1712 & $17 / 09 / 05$ & 06/10/05 & Lost signal & 19 \\
\hline 5 & M & $\mathrm{C} 1$ & 1594 & $17 / 09 / 05$ & $12 / 11 / 05$ & Trapped alive & 57 \\
\hline 6 & M & NW & 2106 & $29 / 11 / 05$ & $19 / 01 / 06$ & RTC & 52 \\
\hline 7 & $\mathrm{~F}$ & NW & 942 & $29 / 11 / 05$ & $19 / 12 / 05$ & Collar off & 21 \\
\hline 8 & $\mathrm{~F}$ & NW & 1064 & $29 / 11 / 05$ & 09/12/05 & Collar off & 11 \\
\hline 9 & $\mathrm{~F}$ & NW & NR & $20 / 10 / 06$ & $22 / 10 / 06$ & RTC & 3 \\
\hline 10 & M & NW & 1183 & $20 / 10 / 06$ & 02/11/06 & RTC & 13 \\
\hline 11 & M & NW & 2074 & $20 / 10 / 06$ & $11 / 11 / 06$ & RTC & 22 \\
\hline 12 & $\mathrm{~F}$ & NW & 889 & $20 / 10 / 06$ & $22 / 01 / 07$ & Lost signal & 94 \\
\hline 13 & $\mathrm{~F}$ & NW & 998 & $20 / 10 / 06$ & $22 / 01 / 07$ & Lost signal & 94 \\
\hline 14 & M & $\mathrm{C} 2$ & 1735 & 03/10/07 & $31 / 10 / 07$ & Collar off & 27 \\
\hline 15 & $\mathrm{~F}$ & $\mathrm{C} 2$ & 975 & 03/10/07 & $15 / 01 / 08$ & $\begin{array}{l}\text { Trapped alive, } \\
\text { collar on }\end{array}$ & 104(265) \\
\hline 16 & F & $\mathrm{C} 2$ & 995 & 03/10/07 & $10 / 11 / 07$ & Collar off & 39 \\
\hline 17 & $\mathrm{~F}$ & $\mathrm{C} 2$ & 939 & 03/10/07 & $01 / 12 / 08$ & $\begin{array}{l}\text { Trapped } \\
\text { collar off }\end{array}$ & $60(258)^{a}$ \\
\hline 18 & $\mathrm{~F}$ & $\mathrm{C} 2$ & 935 & 03/10/07 & $24 / 10 / 07$ & Lost signal & 21 \\
\hline 19 & M & $\mathrm{C} 3$ & 1190 & $27 / 10 / 07$ & 19/11/07 & Lost signal & 23 \\
\hline 20 & $\mathrm{~F}$ & $\mathrm{C} 3$ & 830 & $27 / 10 / 07$ & 07/02/08 & Lost signal & 103 \\
\hline 21 & M & C3 & 2070 & $27 / 10 / 07$ & $05 / 12 / 07$ & Lost signal & 39 \\
\hline 22 & M & $\mathrm{C} 3$ & 2200 & $27 / 10 / 07$ & 05/12/07 & Lost signal & 39 \\
\hline 23 & M & $\mathrm{C} 3$ & 1700 & $27 / 10 / 07$ & $30 / 10 / 07$ & Collar off & 3 \\
\hline 24 & M & $\mathrm{C} 2$ & 1400 & $30 / 09 / 08$ & $21 / 11 / 08$ & Lost signal & $52(138)$ \\
\hline 25 & M & $\mathrm{C} 2$ & 1395 & $30 / 09 / 08$ & $13 / 10 / 08$ & Lost signal & 13 \\
\hline 26 & M & $\mathrm{C} 2$ & 1435 & $30 / 09 / 08$ & $19 / 11 / 08$ & Lost signal & 50 \\
\hline 27 & $\mathrm{~F}$ & $\mathrm{C} 2$ & 825 & $30 / 09 / 08$ & $21 / 10 / 08$ & Collar off & 21 \\
\hline 28 & $\mathrm{~F}$ & $\mathrm{C} 2$ & 970 & $30 / 09 / 08$ & $07 / 11 / 08$ & Lost signal & 38 \\
\hline 29 & M & $\mathrm{S}$ & 1326 & 09/10/08 & 03/11/08 & Lost signal & 25 \\
\hline 30 & $\mathrm{~F}$ & $\mathrm{~S}$ & 795 & 09/10/08 & 06/11/08 & Collar off & 28 \\
\hline 31 & $\mathrm{~F}$ & $\mathrm{~S}$ & 895 & 09/10/08 & $22 / 10 / 08$ & Lost signal & 13 \\
\hline 32 & $\mathrm{~F}$ & $\mathrm{~S}$ & 965 & 09/10/08 & $23 / 10 / 08$ & Lost signal & 14 \\
\hline
\end{tabular}


$30 \mathrm{~cm}$ into the ground to prevent the polecats from escaping during the acclimatisation period. The pens were completed with soil substrate and fresh foliage. Bedding and plastic piping from their runs at Stapeley Grange Wildlife Centre were transported to the release pen with the animals. All release sites were chosen for their suitability of habitat and set up on private land with the landowners' consent. The polecats were allowed to acclimatise to their surrounding for approximately $7 \mathrm{~d}$ before release. During the acclimatisation period and for approximately $7 \mathrm{~d}$ after release, they were supplied with support feed (mice and rabbits). Five dead mice per polecat were provided at dusk on each day, and on Days 3 and 6, 1 fresh rabbit carcass was provided for the group. Support food in similar quantities was provided around the cage for $7 \mathrm{~d}$ after the release. The cage was left in situ for at least $7 \mathrm{~d}$ following release to minimise disturbance.

Trapping. Live-trapping was used to monitor the condition of released polecats. Trapping effort was carried out over a $3 \mathrm{wk}$ period at a release site in Cheshire, under a licence issued to A. K. by Natural England. Ten single-ended mink traps measuring $16 \times$ $18 \times 59 \mathrm{~cm}$ (height $\times$ width $\times$ length) were baited with a dead mouse, placed at random around the release site in a $1 \mathrm{~km}^{2}$ area and checked twice daily. Any trapped polecats were scanned to determine the presence of a microchip, weighed and immediately released.

\section{RESULTS}

\section{Admission reasons and outcomes}

$$
\text { Adults }
$$

Forty-eight adult polecats were admitted between 1997 and 2008. Of those that were sexed $(\mathrm{N}=43)$, $60.5 \%$ were male. Admissions were recorded in all months, with the exception of May. The most common reason for admission was collision with a motor vehicle (51.5\%, Fig. 1). Admission weights ranged from 1041 to $2200 \mathrm{~g}($ median $=1455 \mathrm{~g})$ and 370 to $850 \mathrm{~g}($ median $=$ $694 \mathrm{~g})$, for males $(\mathrm{N}=18)$ and females $(\mathrm{N}=12)$, respectively. The outcomes for all adult polecats are shown in Fig. 2. Twenty adults $(41.6 \%)$ were released back into the wild at the original recovery site. Adult males $(57.7 \%)$ were more likely to be released than females $(29.4 \%)$. Eighteen adult polecats $(37.5 \%)$ were euthanised to prevent further suffering, all but one of these less than $48 \mathrm{~h}$ following admission. Four adult polecats died in care, despite treatment, all within $48 \mathrm{~h}$ of admission. Time in captivity for released adult polecats ranged from $1 \mathrm{~d}$, for those returned to the wild on the same day, to $42 \mathrm{~d}($ median $=11 \mathrm{~d})$.

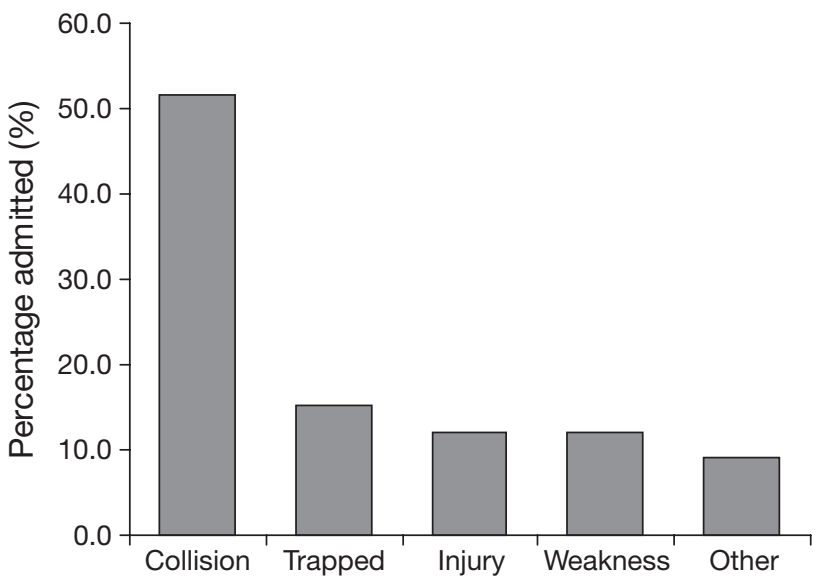

Fig. 1. Mustela putorius. Percentage of adult polecats admitted to Stapeley Grange Wildlife Centre (Cheshire, UK) for different reasons between 1997 and 2008

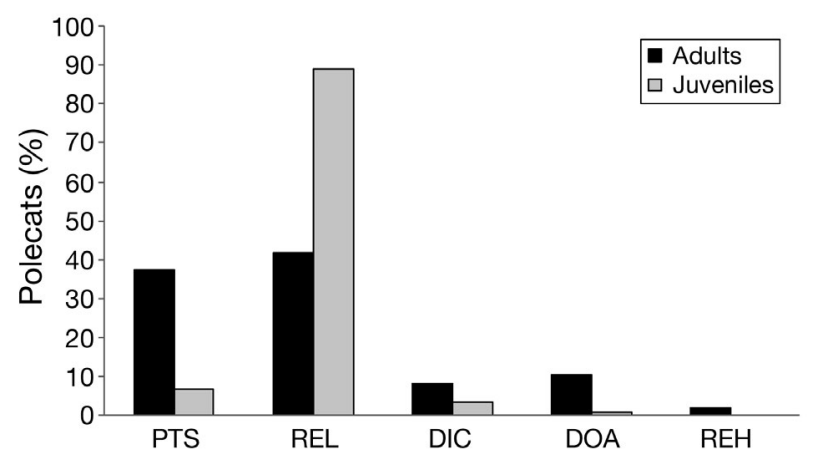

Fig. 2. Mustela putorius. Outcomes for adult and juvenile polecats admitted to Stapeley Grange Wildlife Centre (Cheshire, UK) between 1997 and 2008. PTS: put to sleep (euthanised), REL: released, DIC: died in care, DOA: dead on arrival, REH: rehomed

Juveniles

Eighty-nine juvenile polecats were admitted between 1997 and 2008, of which 52\% were male. The majority of juveniles (70\%) was admitted in June and July of each year. Eighty ( $91 \%$ ) of these were described as 'orphans', with $5(7 \%)$ being the victims of collisions with motor vehicles. A further $2(3 \%)$ had sustained injuries for which the cause was uncertain, and 1 juvenile was rescued after becoming trapped in a compost bin. On admission, weights ranged from 68 to $942 \mathrm{~g}$ (median $=350 \mathrm{~g})$ and 32 to $750 \mathrm{~g}$ (median $=397 \mathrm{~g})$ for males $(\mathrm{N}=$ $16)$ and females $(\mathrm{N}=19)$, respectively. Fig. 2 shows the outcomes for all juvenile polecats admitted between 1997 and 2008. One juvenile polecat was dead on arrival, and 6 were euthanised to prevent further suffering, either on admission or within $48 \mathrm{~h}$. Three died within $48 \mathrm{~h}$ of admission, despite treatment. Seventynine juveniles ( $89 \%$ ) were subsequently released back 
into the wild; of these, $49 \%$ were male. Time in captivity for those individuals subsequently released ranged from 7 to $155 \mathrm{~d}$ (median $=83 \mathrm{~d}$ ).

\section{Radio-tracking}

Between 2005 and 2008, 32 juvenile polecats (17 male and 15 female) were fitted with radio-tracking collars prior to release. All releases took place from mid-September to late November and according to the same protocol (see 'Release protocol'). The release weights (including the collar) ranged from 795 to $1064 \mathrm{~g}$ $($ median $=941 \mathrm{~g})$ and 1183 to $2200 \mathrm{~g}($ median $=1594 \mathrm{~g})$ for females and males, respectively. The fate of all 32 polecats is shown in Table 1. Seven polecats lost their collars; these were retrieved, 3 to $39 \mathrm{~d}$ post-release (median $=21 \mathrm{~d}$ ). The signal was lost for 18 polecats, 13 to $103 \mathrm{~d}$ post-release $($ median $=38.5 \mathrm{~d}$ ). Loss of signal indicated that either the animal had moved out of range and could not be found, the battery life of the transmitter had expired, transmitters had failed or that the animal had died and the transmitter had simultaneously failed. Four polecats were killed in RTCs, 3 to $52 \mathrm{~d}$ postrelease. A further 3 polecats were trapped alive, 57, 60 and $104 \mathrm{~d}$ post-release, respectively. Three of the polecats for which the signal was lost and the polecat that was trapped alive after $104 \mathrm{~d}$ were subsequently the victims of RTCs 68 to $265 \mathrm{~d}$ post-release (Table 1).

\section{Trapping}

Two female polecats were trapped alive, following release in October 2007. One was trapped on 6 occasions between 23 November 2007 and 17 June 2008 (having survived for $258 \mathrm{~d}$ ) and the second on 5 occasions between 27 November 2007 and 15 January 2008. The latter was subsequently found dead, the victim of an RTC, on 24 June 2008, having survived for 265 d post-release. There was considerable change over time in their body weights (Fig. 3). Female 1 had lost $31 \%$ of her release body weight after $258 \mathrm{~d}$, and Female 2 lost $18 \%$ of her body weight within $104 \mathrm{~d}$.

\section{DISCUSSION}

The data presented here provide evidence that orphaned and rehabilitated polecats can survive in the wild following release. Of the 32 radio-tracked polecats, $81 \%$ were alive after $14 \mathrm{~d}$, and a minimum of $50 \%$ were still alive after 1 mo. This compares favourably with the survival of captive-bred European mink Mustela lutreola released in Germany as part of a rein-

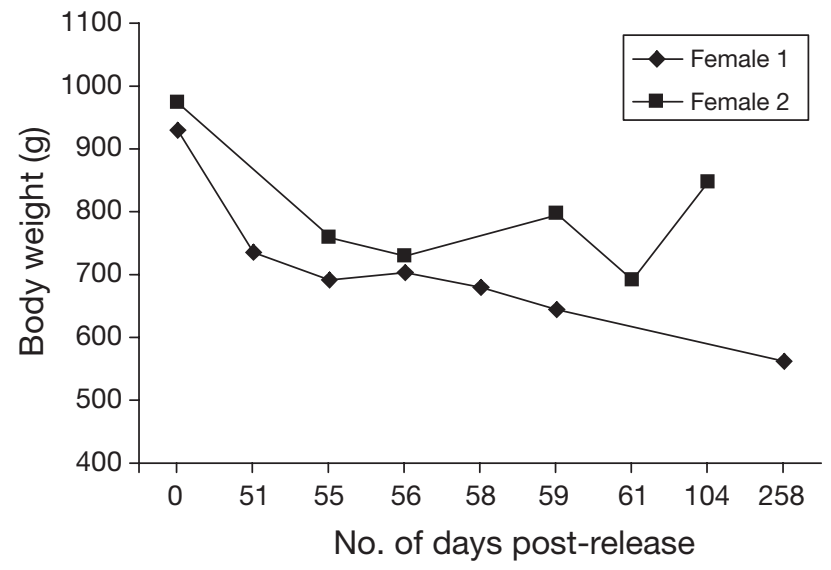

Fig. 3. Mustela putorius. Body weights of 2 female polecats trapped on several occasions following release. Female 1 was trapped alive for the final time $258 \mathrm{~d}$ post-release, and Female 2 was trapped for the last time 104 d post-release. Female 1 was subsequently found dead (road traffic collision) $265 \mathrm{~d}$ post-release

troduction programme, in which a minimum of $60 \%$ and $48 \%$ were confirmed alive after $14 \mathrm{~d}$ and $1 \mathrm{mo}$, respectively (Peters et al. 2009). In that study, $42 \%$ of captive-bred mink fitted with intra-peritoneal transmitters died ( 1 to $86 \mathrm{~d}$ following release). However, the fate of 18 radio-tracked animals was unknown, as the signal was lost and these animals could also have died. In another European mink re-introduction project in Estonia, Maran et al. (2009) reported 59 and $30 \%$ alive after $14 \mathrm{~d}$ and $1 \mathrm{mo}$, respectively, with $37 \%$ confirmed as having died. For black-footed ferrets in North America, Biggins et al. (1998) reported only $30 \%$ still alive after $30 \mathrm{~d}$. In the current study, only 9 polecats $(28 \%)$ were confirmed to have died. However, the fate of the other 23, once the signal had been lost, is not known, and these animals may also have died. Although the 9 polecats confirmed to have died were the victims of RTCs, this cannot be seen as a failure of the rehabilitation process. Mortality as a result of RTCs is common in polecat populations, with up to $70 \%$ of juvenile polecats being killed on the roads in their first year (Birks 2008). We should expect a similar percentage of released polecats to be killed by RTCs. Indeed, RTCs are a major mortality factor for wildlife in general (Loos \& Kerlinger 1993, Philcox et al. 1999, Fajardo et al. 2000). Polecats are known to take some food as carrion (Birks \& Kitchener 2008), and this makes them vulnerable to being killed in RTCs as they may scavenge road-killed rabbits. It has recently been demonstrated that the presence of rabbits close to roads increases polecat mortality in a Spanish population (Barrientos \& Bolonio 2009).

Of the 32 polecats radio-tracked in this study, 7 $(22 \%)$ lost their collars within 3 to $39 \mathrm{~d}$, 4 were killed 
by RTCs within $52 \mathrm{~d}$ ( 3 of these within $22 \mathrm{~d}$ ) and the signal was lost for 18. It is not clear whether collar loss was the result of failure of the collar attachment or due to the animals losing weight and the collar becoming looser and subsequently falling off. However, all recovered collars were complete, suggesting that the animals may have lost weight and the collars slipped off. We cannot, however, be sure that collar loss is attributable to weight loss: 2 of the female polecats that were trapped in 2007 had lost up to $31 \%$ of bodyweight, but one of these had lost the collar and the other had retained it. Loss of signal could have been due to expiration of battery life, failure of the transmitter, death of the animal and failure of the transmitter, or the animal simply moving out of range and not being found. Transmitters were fitted with mortality sensors, which transmitted a constant signal if the transmitter had not moved for $6 \mathrm{~h}$. Therefore, it is unlikely that an animal could die within range of the receivers and not be located unless the transmitter had been damaged. Five of the polecats for which the signal was lost were subsequently relocated. Three of these, tracked for 18, 52 and $58 \mathrm{~d}$, were subsequently found freshly dead, victims of RTCs, 172, 138 and $68 \mathrm{~d}$ post-release, respectively. Two were trapped alive on several occasions up to 104 and 258 d post-release, respectively, with the former being found dead $265 \mathrm{~d}$ after release, the victim of an RTC. The data for these 5 polecats suggest that those animals for which the signal was lost may have simply moved out of the area and despite extensive searches were not re-discovered. However, we have no knowledge of the fate of the 13 polecats for which the signal was lost, and they may well have died. One of those subsequently relocated (found dead after $68 \mathrm{~d}$ ) was found to have remains of a wild rabbit in its stomach on post mortem, indicating that it had been feeding on natural food sources, although it could have scavenged a road-kill rabbit, making it vulnerable to being killed by an RTC. Two female polecats were trapped on several occasions and were found to have lost $31 \%$ and $18 \%$ of their body weight. One was subsequently found dead (the victim of an RTC) $265 \mathrm{~d}$ post-release. On release, these 2 females weighed 975 and $930 \mathrm{~g}$, within the range for female polecats in the West Midlands (Birks \& Kitchener 2008), but 24 and $18 \%$, respectively, above the mean (787 g). Unfortunately, we were only able to trap a small number of released polecats, and more trapping effort is required to assess long-term survival and body condition.

Wildlife rehabilitation is often criticised as having no conservation value and being a waste of time and resources (Sharp 1996). However, wildlife rehabilitation is usually undertaken from an animal welfare perspective. The failure of many reintroduction or translo- cation programmes may compromise the welfare of individual animals involved in these projects. Although Griffith et al. (1989) reported a low success rate for translocations, a review of these programmes indicated an increase in the number resulting in selfsustaining populations, with $67 \%$ subsequently being described as successful. However, Fischer \& Lindenmayer (2000) reported that only $26 \%$ of 116 programmes could be described as successful, although a further $47 \%$ were uncertain. We do not know what percentage of successful or failed projects fulfilled IUCN guidelines or used suitable release stock (IUCN 1998). Given that translocation and reintroduction programmes using wild-caught animals are more successful that those using captive-bred animals (Griffith et al. 1989, Wolf et al. 1996, Fischer \& Lindenmayer 2000, Hayward et al. 2007, Jule et al. 2008), rehabilitated wildlife may be a valuable source of animals for conservation programmes if it can be demonstrated that rehabilitated wildlife can survive independently following release. For example, the reintroduction of rehabilitated orangutan Pongo pygmaeus and Bornean gibbons Hylobates muelleri has contributed to the conservation of these critically endangered species (Cheyne 2007, Russon 2009). Wildlife rehabilitation can make a valuable contribution to the reintroduction and conservation of endangered species. We believe that rehabilitated polecats could be used to reinforce or supplement existing populations or could be reintroduced to former parts of their range, circumstances that would fulfil the IUCN guidelines on reintroductions (IUCN 1998, Macdonald 2009).

There are thought to be in excess of 650 wildlife rehabilitation centres in the UK, with as many as 30000 to 40000 animals being taken into care annually (Molony et al. 2007). However, this 'profession' is largely unregulated and has no governing body responsible for setting and monitoring standards. In addition, there is no requirement for formal training as there is in much of the USA. Consequently, there is little scientific basis for the work and little information about what is being achieved. Return to the wild is often seen as 'success', despite the fact that in most cases wildlife rehabilitators have little or no knowledge of the post-release survival of wildlife casualties. This has clear and obvious implications for the welfare of the animals involved. Some rehabilitators view euthanasia as a failure, rather than a welfare tool, and those that do use euthanasia as a welfare tool, such as the RSPCA, are often criticised for it. The ethics of interventions for the welfare of free-living wild animals were discussed by Kirkwood \& Sainsbury (1996). They suggested that wildlife rehabilitation is justifiable under certain conditions, particularly where human activities have directly or indirectly resulted 
in the requirement for intervention. Euthanasia on welfare grounds is justifiable if wildlife casualties are unlikely to recover and are in pain or distress. This forms the basis of the RSPCA policy on wildlife rehabilitation, which states that rehabilitation will only be attempted if there is a good chance of return to the wild.

There is now a body of evidence emerging that wildlife rehabilitation is successful based on the postrelease survival of the animals involved (Leighton et al. 2008, Kelly et al. 2008, present study). Kelly et al. (2008) radio-tracked 5 hand-reared, orphaned pipistrelle bats for between 5 and 10 nights, demonstrating that these animals were able to survive, at least in the short term. A further 10 bats have since been radiotracked for similar time periods, and 6 ringed bats exhibited minimum post-release survival ranging from 27 to 236 d (A. Kelly unpubl. data). Using radio-tracking and leg-band returns, Leighton et al. (2008) showed that hand-reared, orphaned tawny owls could survive independently in the wild. Thirteen birds were radio-tracked for between 16 and $84 \mathrm{~d}$ (median = $38 \mathrm{~d}$ ). Thirty-five percent were radio-tracked for more than $6 \mathrm{wk}$, the time period considered to indicate successful rehabilitation of raptors, since the birds are clearly capable of hunting independently (Martell et al. 1991, 2000). Leg-band returns demonstrated longer-term survival. Of 112 birds banded, $18 \%$ were recovered, with the time elapsed between release and recovery ranging from 1 to $2246 \mathrm{~d}$ (median = $123 \mathrm{~d}$ ). The legband recovery data showed that $65 \%$ survived longer than the critical 6 wk period (Leighton et al. 2008).

We believe that the rehabilitation and release of polecats in the UK serves a useful conservation purpose but is also justified from an animal welfare perspective. In the future, we hope to compare our postrelease survival data for wild-born, orphaned polecats with those for captive-bred polecats when those data become available. In the meantime, we recommend that wildlife rehabilitators undertake more postrelease survival work to determine whether their methods of rehabilitation can be considered successful. We would also encourage further collaboration between wildlife rehabilitators, conservationists and ecologists to examine the merits of wild-born individuals versus captive-bred individuals for use in reintroduction or translocation projects.

Acknowledgements. This project was funded by the RSPCA through the Scientific, Technical and Academic Committee. We thank T. Coleshaw of Natural England for permission to release polecats on a Natural England National Nature Reserve in Cheshire, J. Daniels for permission to release polecats at a Nature Reserve in Shropshire, and J. Thompson, Warden of Pensychnant Conservation Centre and Nature Reserve for permission to release polecats in North Wales. We also thank all landowners who gave us access for releases and radio-tracking. Thanks to all staff and volunteers who gave up their time to carry out the radio-tracking. Polecats were trapped under licence nos. 20052219, 20062097 and 20072555 issued by English Nature to A.K. and 20083511 issued by Natural England to A.K.

\section{LITERATURE CITED}

Bar-David S, Saltz D, Dayan T, Perelberg A, Dolev A (2005) Demographic models and reality in reintroductions: Persian fallow deer in Israel. Conserv Biol 19:131-138

Barrientos R, Bolonio L (2009) The presence of rabbits adjacent to roads increases polecat road mortality. Biodivers Conserv 18:405-418

Beck BB, Rapaport LG, Price MRS, Wilson AC (1994) Reintroduction of captive-born animals. In: Olney PJS, Mace GM, Feistner ATC (eds) Creative conservation: interactive management of wild and captive animals. Chapman \& Hall, London, p 265-284

> Biggins DE, Godbey JL, Hanebury LR, Luce B, Marinari PE, Matchett MR, Vargas A (1998) The effect of rearing methods on survival of reintroduced black-footed ferrets. J Wildl Manag 62:643-653

Birks JDS (2000) The recovery of the polecat (Mustela putorius) in Britain. In: Griffiths HI (ed) Mustelids in a modern world: management and conservation aspects of small carnivore:human interactions. Blackhuys, Leiden, p 141-152

Birks JDS (2008) The Polecat Survey of Britain 2004-2006: a report on the polecat's distribution, status and conservation. Vincent Wildlife Trust, London

Birks JDS, Kitchener AC (1999) The distribution and status of the polecat (Mustela putorius) in Britain in the 1990s. Vincent Wildlife Trust, London

Birks JDS, Kitchener AC (2008) Polecat. In: Harris S, Yalden DW (eds) Mammals of the British Isles: handbook, 4th edn. The Mammal Society, Southampton, p 476-485

- Blandford PRS (1987) Biology of the polecat Mustela putorius: a literature review. Mammal Rev 17:155-198

Cheyne SM (2007) The role of reintroduction in gibbon conservation: opportunities and challenges. In: Lappan SM, Whittaker DL, Geissmann T (eds) The gibbons: new perspectives on small ape socioecology and population biology. Springer, New York, NY, p 477-496

Fajardo I, Babiloni G, Miranda Y (2000) Rehabilitated and wild barn owls (Tyto alba): dispersal, life expectancy and mortality in Spain. Biol Conserv 94:287-295

Fischer J, Lindenmayer DB (2000) An assessment of the published results of animal relocations. Biol Conserv 96:1-11

Ginsberg JR (1994) Captive breeding, reintroduction and the conservation of canids. In: Olney PJS, Mace GM, Feistner ATC (eds) Creative conservation: interactive management of wild and captive animals. Chapman \& Hall, London, p 265-284

Griffith B, Scott JM, Carpenter JW, Reed C (1989) Translocation as a species conservation tool - status and strategy. Science 245:477-480

Hayward MW, Adendorff J, O'Brien JO, Sholto-Douglas A and others (2007) Practical considerations for the reintroduction of large, terrestrial, mammalian predators based on reintroductions to South Africa's Eastern Cape Province. Open Conserv Biol J 1:1-11.

IUCN (1998) Guidelines for re-introductions. Prepared by the IUCN/SSC Re-introduction Specialist Group. IUCN, Gland and Cambridge

> Jule KR, Leaver LA, Lea SEG (2008) The effects of captive experience on reintroduction survival in carnivores: a 
review and analysis. Biol Conserv 141:355-363

Kelly A, Bland M (2006) Admissions, diagnoses, and outcomes for Eurasian sparrowhawks (Accipiter nisus) brought to a wildlife rehabilitation center in England. J Raptor Res 40:231-235

Kelly A, Goodwin S, Grogan A, Mathews F (2008) Postrelease survival of hand-reared pipistrelle bats (Pipistrellus spp.). Anim Welf 17:375-382

Kirkwood JK, Sainsbury AW (1996) Ethics of interventions for the welfare of free-living wild animals. Anim Welf 5: 235-243

Langley PJW, Yalden DW (1977) The decline of the rarer carnivores in Great Britain during the nineteenth century. Mammal Rev 7:95-116

Leighton K, Chilvers D, Charles A, Kelly A (2008) Post-release survival of hand-reared tawny owls (Strix aluco) based on radio tracking and band return data. Anim Welf 17: 207-214

Letty J, Marchandeau S, Aubineau J (2007) Problems encountered by individuals in animal translocations: lessons from the field. Ecoscience 14:420-431

Linklater WL, MacDonald EA, Flamand JRB, Czekala NM (2010) Declining and low fecal corticoids are associated with distress, not acclimation to stress, during the translocation of African rhinoceros. Anim Conserv 13: 104-111

Loos G, Kerlinger P (1993) Road mortality of saw-whet and screech-owls on the Cape May peninsula. J Raptor Res 27 : $210-213$

Macdonald DW (2009) Lessons learnt and plans laid: seven awkward questions for the future of reintroductions. In: Hayward MW, Somers MJ (eds) Reintroduction of toporder predators. Wiley-Blackwell, Oxford, p 411-448

Maran T, Põdra M, Põlma M, Macdonald DW (2009) The survival of captive-born animals in restoration programmes case study of the endangered European mink Mustela lutreola. Biol Conserv 142:1685-1692

Martell MS, Redig PT, Nibe J, Buhl G (1991) Survival and movements of released rehabilitated bald eagles. J Raptor Res 25:72-76

Martell MS, Goggin J, Redig PT (2000) Assessing rehabilitation success of raptors through band returns. In: Lumeij JT, Remple D, Redig PT, Lierz M, Cooper JE (eds) Raptor biomedicine III, including bibliography of diseases of birds of prey. Zoological Education Network, Lake Worth, FL, p 327-334

Mathews F, Orros M, McLaren G, Gelling M, Forster R (2005) Keeping fit on the ark: assessing the suitability of captivebred animals for release. Biol Conserv 121:569-577

Mathews F, Moro D, Strachan R, Gelling M, Buller N (2006) Health surveillance in wildlife reintroductions. Biol Con-

Editorial responsibility: Wayne Linklater, Wellington, New Zealand serv 131:338-347

> Molony SE, Dowding CV, Baker PJ, Cuthill IC, Harris S (2006) The effect of translocation and temporary captivity on wildlife rehabilitation success: an experimental study using European hedgehogs (Erinaceus europaeus). Biol Conserv 130:530-537

Molony SE, Baker PJ, Garland L, Cuthill IC, Harris S (2007) Factors that can be used to predict release rates for wildlife casualties. Anim Welf 16:361-367

Moorhouse T (2004) Factors affecting the success of reintroduction as a species tool for the water vole (Arvicola terrestris). Environment Agency Science Report W1-040/TR

Moorhouse T, Gelling M, McLaren GW, Mian R, Macdonald DW (2007) Physiological consequences of captive conditions in water voles (Arvicola terrestris). J Zool (Lond) 271: $19-26$

Packer JJ, Birks JDS (1999) An assessment of British farmers' and gamekeepers' experiences, attitudes and practices in relation to the European polecat Mustela putorius. Mammal Rev 29:75-92

Peters E, Brinkmann I, Krüger F, Zwirlein S, Klaumann I (2009) Reintroduction of the European mink Mustela lutreola in Saarland, Germany. Preliminary data on the use of space and activity as revealed by radio-tracking and live trapping. Endang Species Res 10:305-320

Philcox CK, Grogan AL, Macdonald DW (1999) Patterns of otter Lutra lutra road mortality in Britain. J Appl Ecol 36: 748-762

> Pinter-Wollman N, Isbell LA, Hart LA (2009) Assessing translocation outcome: comparing behavioral and physiological aspects of translocated and resident African elephants (Loxodonta africana). Biol Conserv 142:1116-1124

Russon AE (2009). Orangutan rehabilitation and reintroduction. In: Wich SA, Utami SS, Mitra Setia T, van Schaik CP (eds) Orangutans: geographic variation in behavioral ecology and conservation. Oxford University Press, Oxford, p 327-350

Sarrazin F, Legendre S (2000) Demographic approach to releasing adults versus young in reintroductions. Conserv Biol 14:488-500

Sharp B (1996) The post-release survival of oiled, cleaned seabirds in North America. Ibis 138:222-228

- Teixeira CP, Schetini de Azevedo C, Mendl M, Cipreste CF, Young RJ (2007) Revisiting translocation and reintroduction programmes: the importance of considering stress. Anim Behav 73:1-13

White GC, Garrott A (1990) Analysis of wildlife radio-tracking data. Academic Press, London

Wolf CM, Griffith B, Reed C, Temple SA (1996) Avian and mammalian translocations: update and reanalysis of 1987 survey data. Conserv Biol 10:1142-1154

Submitted: December 30, 2009; Accepted: June 16, 2010

Proofs received from author(s): July 2, 2010 